\title{
Nickel quercetinase, a "promiscuous" metalloenzyme: metal incorporation and metal ligand substitution studies
}

\author{
Dimitrios Nianios ${ }^{1}$, Sven Thierbach ${ }^{1}$, Lenz Steimer ${ }^{2}$, Pavel Lulchev ${ }^{2}$, Dagmar Klostermeier ${ }^{2}$ and Susanne Fetzner ${ }^{\text {** }}$
}

\begin{abstract}
Background: Quercetinases are metal-dependent dioxygenases of the cupin superfamily. While fungal quercetinases are copper proteins, recombinant Streptomyces quercetinase (QueD) was previously described to be capable of incorporating $\mathrm{Ni}^{2+}$ and some other divalent metal ions. This raises the questions of which factors determine metal selection, and which metal ion is physiologically relevant.

Results: Metal occupancies of heterologously produced QueD proteins followed the order $\mathrm{Ni}>\mathrm{Co}>\mathrm{Fe}>\mathrm{Mn}$. Iron, in contrast to the other metals, does not support catalytic activity. QueD isolated from the wild-type Streptomyces sp. strain FLA contained mainly nickel and zinc. In vitro synthesis of QueD in a cell-free transcription-translation system yielded catalytically active protein when $\mathrm{Ni}^{2+}$ was present, and comparison of the circular dichroism spectra of in vitro produced proteins suggested that $\mathrm{Ni}^{2+}$ ions support correct folding. Replacement of individual amino acids of the $3 \mathrm{His} / 1 \mathrm{Glu}$ metal binding motif by alanine drastically reduced or abolished quercetinase activity and affected its structural integrity. Only substitution of the glutamate ligand (E76) by histidine resulted in Ni- and Co-QueD variants that retained the native fold and showed residual catalytic activity.

Conclusions: Heterologous formation of catalytically active, native QueD holoenzyme requires $\mathrm{Ni}^{2+}, \mathrm{Co}^{2+}$ or $\mathrm{Mn}^{2+}$, i.e., metal ions that prefer an octahedral coordination geometry, and an intact $3 \mathrm{His} / 1 \mathrm{Glu}$ motif or a $4 \mathrm{His}$ environment of the metal. The observed metal occupancies suggest that metal incorporation into QueD is governed by the relative stability of the resulting metal complexes, rather than by metal abundance. $\mathrm{Ni}^{2+}$ most likely is the physiologically relevant cofactor of QueD of Streptomyces sp. FLA.
\end{abstract}

Keywords: Dioxygenase, Flavonol, Metalloprotein, Nickel, Coordination geometry, Cell-free protein synthesis

\section{Background}

Quercetinase (flavonol dioxygenase, EC 1.13.11.24) catalyzes the 2,4-dioxygenolytic cleavage of quercetin, a flavonol that is produced by numerous plants, to form carbon monoxide and the depside (diphenolic ester) 2protocatechuoylphoroglucinol carboxylic acid (Scheme 1). The bacterial and fungal quercetinases that have been characterized to date all belong to the cupin superfamily [1-4]. The cupin domain is characterized by a $\beta$-barrel fold which comprises two conserved motifs with the consensus sequences $\mathrm{G}(\mathrm{X})_{5} \mathrm{HXH}(\mathrm{X})_{3,4} \mathrm{E}(\mathrm{X})_{6} \mathrm{G}$ and $\mathrm{G}(\mathrm{X})_{5} \mathrm{PXG}(\mathrm{X})_{2}$ $\mathrm{H}(\mathrm{X})_{3} \mathrm{~N}$. The conserved glutamate and the three histidine

\footnotetext{
*Correspondence: fetzner@uni-muenster.de

${ }^{1}$ Institute of Molecular Microbiology and Biotechnology, University of

Muenster, Corrensstrasse 3, Muenster D-48149, Germany

Full list of author information is available at the end of the article
}

residues provide the ligands for a divalent metal ion in the active center of the enzyme [5] (Figure 1). Among the fungal quercetinases, the enzyme of Aspergillus japonicus has been characterized most intensively [1,6-9]. It is an extracellular glycoprotein with a bicupin scaffold, i.e., each subunit consists of two cupin domains. Two examples of bacterial quercetinases have been reported; both are cytoplasmic proteins. The enzyme of Bacillus subtilis consists of bicupin subunits that form a homodimer [2], whereas the enzyme of Streptomyces sp. FLA, which shows $35.9 \%$ sequence identity with the C-terminal cupin domain of Bacillus quercetinase, is a dimer of monocupin subunits $[3,10]$.

The majority of dioxygenases require a metal cofactor for catalysis, which is most often a nonheme iron [11]. Interestingly, all the extracellular fungal quercetinases 
<smiles>CC(C)C(C)OC(C)C(C)O</smiles>

Scheme 1 Conversion of quercetin to 2-protocatechuoylphloroglucinol carboxylic acid, catalyzed by quercetinase (flavonol 2,4-dioxygenase).

isolated so far rely on a mononuclear copper center for activity $[1,4,12-14]$, whereas the cytoplasmic quercetinases of B. subtilis and Streptomyces sp. FLA appear to be promiscuous enzymes capable of using different metal ions for catalysis. Bacillus quercetinase has originally been purified from a recombinant $E$. coli host grown in LB (Lysogeny Broth) as an iron protein $[2,15,16]$. Reconstitution experiments suggested that $\mathrm{Co}, \mathrm{Cu}$, and $\mathrm{Mn}$ also support catalysis [2], and characterization of the kinetic parameters of the $\mathrm{Mn}$ - and $\mathrm{Co}$-forms revealed that the catalytic efficiency was highest for the $\mathrm{Mn}$ enzyme [17]. In contrast to Bacillus QueD, Streptomyces QueD, purified from recombinant $E$. coli cells grown with various metal ions, was found to be most active with $\mathrm{Ni}^{2+}$, which is highly unusual for oxygenases [3]. However, in this as well as in other studies on bacterial quercetinases, the proteins were heterologously produced in E. coli. As pointed out in a recent review, when using a highexpression heterologous system for the synthesis of $\mathrm{Ni}$-QueD, "the relevance to metal speciation of protein in the native host remains unclear" [18].

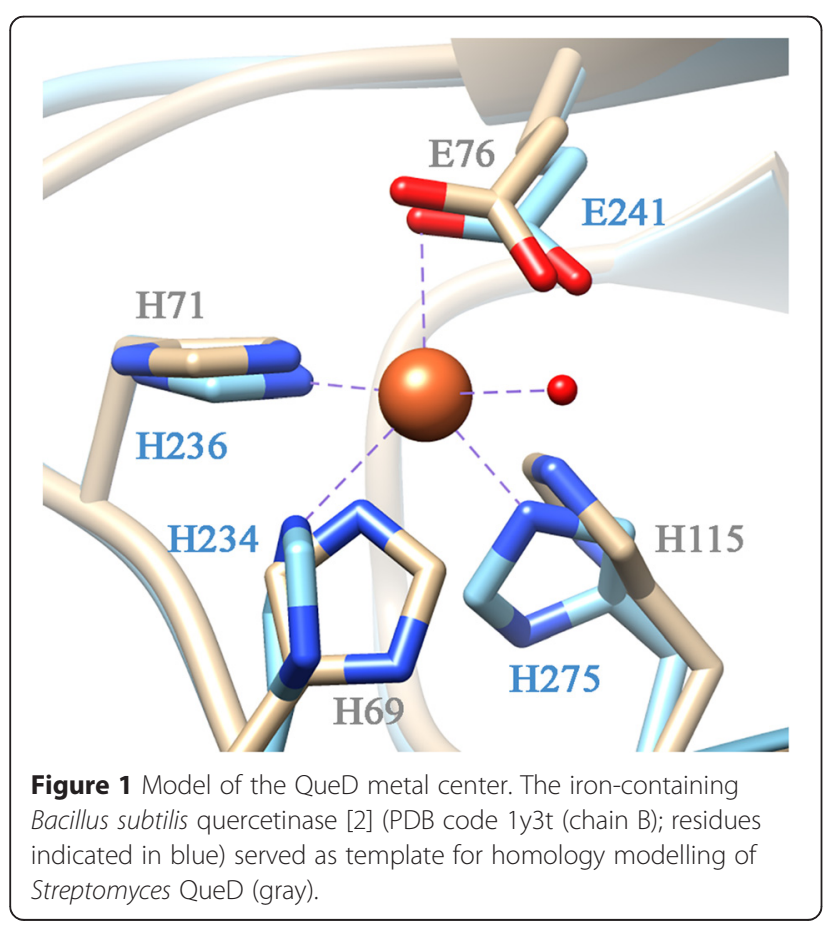

Streptomyces sp. strain FLA grows very poorly on quercetin as sole carbon source [10]. Transcription of the $q u e D$ gene of strain FLA is induced by quercetin, however, the regulatory mechanism remained elusive. An effect of $\mathrm{Ni}^{2+}$ on queD expression was not observed [19]. Because quercetin shows antibacterial activity, acting on multiple cellular targets [20-23], it is conceivable that a major physiological role of quercetinase is to detoxify the flavonol. The quercetin O-methylation, hydroxylation, or glycosylation reactions mediated by various Streptomyces spp. $[24,25]$ may serve the same function.

In this study, we prepared different metal forms of Streptomyces QueD by in vivo and in vitro approaches, to identify the physiologically relevant metal cofactor(s), and to find out which factors determine metal selection. Replacement of individual residues of the $3 \mathrm{His} / 1 \mathrm{Glu}$ motif gave insight into the significance of the amino acid ligands for metal occupancy, protein folding, and function.

\section{Results}

Metal selectivity and catalytic activity of recombinant QueD To enable a systematic study of the metal selectivity of QueD, as well as of the effects of different transition metal ions on quercetinase activity, we produced the enzyme recombinantly in $E$. coli which was grown in media supplemented with an excess of the metal ion of interest. Preparations of C-terminally Strep-tagged QueD, purified to electrophoretic homogeneity from cells grown in $\mathrm{Ni}^{2+}$-supplemented medium (Additional file 1: Figure S1), generally contained about $0.6-0.8$ equivalents of nickel per protein monomer. Cobalt contents of QueD isolated from cells grown in $\mathrm{CoCl}_{2}$-supplemented medium varied significantly between the batches $(0.5$ to $>1$ equivalent per protein monomer). QueD protein produced by recombinant E. coli grown in $\mathrm{Fe}^{2+}$-supplemented medium showed varying iron contents in the range of 0.3 to 0.8 equivalents of iron per protein monomer. When QueD was purified from cells grown in medium supplemented with $30 \mu \mathrm{M}$ $\mathrm{MnCl}_{2}$, the proteins contained only between 0.2 to 0.5 equivalents of $\mathrm{Mn}$ and varying amounts of other metals, predominantly $\mathrm{Ni}$, but also $\mathrm{Fe}$ and $\mathrm{Zn}$. Increasing the concentration of $\mathrm{MnCl}_{2}$ in the cultivation medium to $1 \mathrm{mM}$ did not increase the Mn occupancy of the recombinant protein. To assess the effect of the metal ion on the overall structure of the protein, the CD spectra of $\mathrm{Ni}$-, 
Co-, Fe- and Mn-QueD produced in vivo were recorded. The spectra were very similar and characteristic of proteins that are predominantly composed of $\beta$-sheets (Figure 2A).

The catalytic activity of the recombinant proteins decreased in the order Ni-QueD $>$ Co-QueD $>$ Mn-QueD (Table 1). An estimation of the metal-related specific activities of QueD forms, i.e., the specific activities if QueD were fully occupied with the metal of interest (Additional file 2: Table S1), suggests that the iron form of QueD is not catalytically competent.

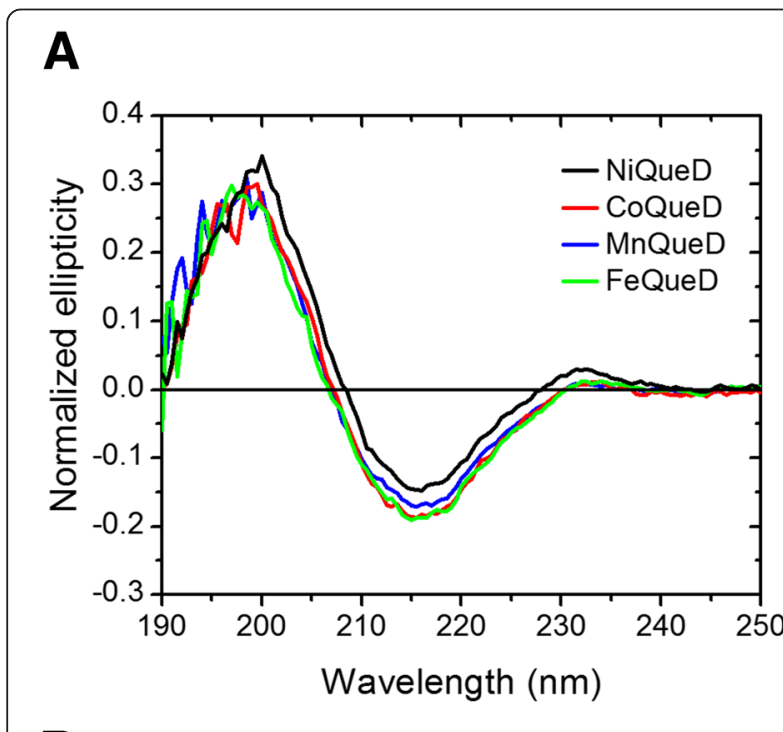

\section{B}

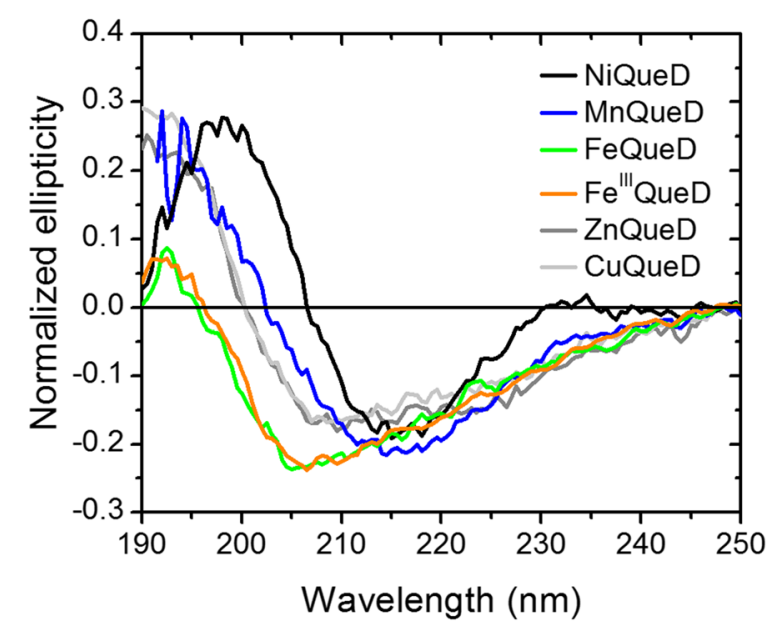

Figure 2 Far-UV CD spectra of QueD proteins produced in vivo and in vitro. (A), Proteins purified from recombinant E. coli cells, and (B), proteins synthesized in vitro by cell-free protein synthesis in presence of $1 \mathrm{mM} \mathrm{Ni}^{2+}, \mathrm{Mn}^{2+}$, or iron salts, or $0.2 \mathrm{mM} \mathrm{Cu}^{2+}$ or $\mathrm{Zn}^{2+}$. Protein samples in $10 \mathrm{mM}$ potassium phosphate buffer $(\mathrm{pH} 8.0)$ were adjusted to $10 \mu \mathrm{M}$ (based on measuring absorbance at $280 \mathrm{~nm}$ ). Spectra were recorded at $25^{\circ} \mathrm{C}$ in a $1 \mathrm{~mm}$ path length cell; bandwidth: $0.1 \mathrm{~nm}(\mathbf{A})$ or $0.5 \mathrm{~nm}$ (B).
Characterization of a Zn-form of QueD would be very interesting from a mechanistic point of view, because the $\mathrm{Zn}^{2+}$ ion is redox-inert in biological systems. However, attempts to produce $\mathrm{Zn}$-QueD by the in vivo approach resulted in protein preparations that contained nickel rather than zinc (up to 0.67 equivalents of $\mathrm{Ni}$ and between 0.1 and 0.26 equivalents of $\mathrm{Zn}$ per protein monomer).

Since fungal quercetinases depend on a $\mathrm{Cu}^{2+}$ center, it also would be interesting to characterize a $\mathrm{Cu}$-form of the bacterial QueD. However, in the reducing environment of the E. coli cytoplasm, copper ions are in the $\mathrm{Cu}^{1+}$ state, and attempts to produce $\mathrm{Cu}$-QueD by the standard expression system were not successful. Fusing QueD to PelB- or DsbA-leader peptides in order to secrete the recombinant QueD to the E. coli periplasm resulted in formation of intracellular rather than periplasmic protein, precluding the production of $\mathrm{Cu}-\mathrm{QueD}$ by periplasmic $\mathrm{Cu}^{2+}$ incorporation.

In summary, the order of metal ions according to occupancy of recombinant QueD is $\mathrm{Ni} \approx \mathrm{Co}>\mathrm{Fe}>\mathrm{Mn}$, while in terms of activity we observe the ranking $\mathrm{Ni}>\mathrm{Co}>\mathrm{Mn}$.

\section{QueD from the wild-type strain, Streptomyces sp. FLA}

The bacterial quercetinases described to date were all produced heterologously in E. coli. They were observed to be promiscuous with respect to metal ion incorporation, thus their natural cofactor(s) incorporated by the original wildtype strain remained unassigned [2,3,10,15-17]. Using a four-step protocol, QueD from Streptomyces sp. FLA was purified to approximately $91 \%$ electrophoretic homogeneity, as deduced from densitometric analysis of the Coomassie-stained gel (Additional file 1: Figure S1). According to ICP-MS (inductively coupled plasma mass spectrometry) analysis, the protein preparation contained $0.33,0.28,0.16$ and 0.02 equivalents of $\mathrm{Ni}$, $\mathrm{Zn}, \mathrm{Fe}$ and $\mathrm{Cu}$, respectively, per monomer. We cannot exclude the possibility that the purification protocol enriches distinct metal forms of QueD, however, QueD activity eluted as distinct peaks from the columns. Because heterologously produced QueD can incorporate cobalt or manganese besides nickel and iron (see above), it is remarkable that the content of these metals was below detection, especially as the mineral salts medium used for growth of Streptomyces contained $\mathrm{CoCl}_{2}(8.4 \mathrm{nM})$ and $\mathrm{MnCl}_{2}(1.5 \mathrm{nM})$ besides $\mathrm{NiCl}_{2}(0.8 \mathrm{nM})$. The relatively high contents of zinc in the protein preparation were surprising. The growth medium was supplemented with $3.5 \mathrm{nM} \mathrm{ZnSO}$, but as cells accumulate metal ions to a different extent, zinc may be concentrated by a high factor. The protein preparation, which contained minor amounts of other proteins, showed a specific activity of $49 \mathrm{U} \mathrm{mg}^{-1}$ (Additional file 3: Table S2). Considering that recombinant QueD with a nickel occupancy of 33\% 
Table 1 Metal contents and specific activities of selected batches of recombinant QueD proteins

\begin{tabular}{lll}
\hline Protein $^{\mathbf{a}}$ & Metal content (equivalents per protein monomer) & Specific activity (U mg $^{-1}$ ) \\
\hline Ni-QueD & $0.70 \mathrm{Ni}, 0.20 \mathrm{Fe}, 0.03 \mathrm{Co}, 0.06 \mathrm{Zn}, 0.01 \mathrm{Mn}$ & 137 \\
Co-QueD & $0.51 \mathrm{Co}, 0.07 \mathrm{Ni}, 0.05 \mathrm{Fe}, 0.02 \mathrm{Zn}, 0.01 \mathrm{Mn}, 0.01 \mathrm{Cu}$ & 30 \\
Mn-QueD & $0.44 \mathrm{Mn}, 0.12 \mathrm{Zn}, 0.08 \mathrm{Fe}, 0.05 \mathrm{Ni}, 0.01 \mathrm{Co}, 0.01 \mathrm{Cu}$ & 18 \\
Fe-QueD & $0.72 \mathrm{Fe}, 0.05 \mathrm{Ni}, 0.02 \mathrm{Zn}, 0.02 \mathrm{Cu}, 0.01 \mathrm{Mn}$ & 8 \\
\hline
\end{tabular}

${ }^{a}$ The designations of the QueD metal forms refer to the metal of interest and do not imply exclusive occupancy of the protein with this metal. Metal ions which contribute to $\geq 0.01$ equivalents per protein monomer are listed.

should have a specific activity of about $60 \mathrm{U} \mathrm{mg}^{-1}$ ( $c f$. Additional file 2: Table S1), the catalytic activity of wildtype QueD is likely mediated by a $\mathrm{Ni}^{2+}$ center.

\section{Cell-free protein synthesis (CFPS) of QueD in the presence of metal ions}

From the analysis of QueD proteins produced in vivo, it is difficult to assess to which extent metal ion availability and/or intrinsic preferences of the protein determine metal incorporation. To exclude effects caused by the limited in vivo availability of free metal ions, we aimed at producing QueD using in vitro approaches. However, in vitro reconstitution experiments, following protocols used for other cupin proteins $[2,26]$, resulted in precipitation of QueD. Therefore, we tested an E. coli cell-free coupled transcription-translation system for production of different metal forms of the QueD protein. There are relatively few studies on cell-free synthesis of metalloproteins in the literature. For example, successful synthesis by in vitro transcription-translation systems was reported for manganese peroxidase (a heme protein) [27], a ferredoxin [28], [FeFe] hydrogenase [29], and Cu,Zn-superoxide dismutase [30]. The yields reported were in the range of about $30-50 \mu \mathrm{g} \mathrm{ml}^{-1}[27,29,30]$ or lower and seldom reached several $100 \mu \mathrm{g}$ of protein from $1 \mathrm{ml}$ reaction [28]. Often only part of the total protein was functional $[27,29]$.

In order to identify suitable conditions for CFPS in the presence of metal ions, we first used a QueD-EGFP fusion protein as reporter, and determined the relative protein level by measuring EGFP fluorescence during CFPS. At concentrations below or equal to $1 \mathrm{mM}$ of $\mathrm{Ni}^{2+}, \mathrm{Fe}^{2+}$, or $\mathrm{Mn}^{2+}$, the relative EGFP fluorescence intensities in the coupled transcription-translation reactions were similar to those observed in CFPS reactions performed in the absence of additional metal ions (Additional file 4: Figure S2 A - C, F), suggesting that these metals do not significantly affect translational efficiency in general. In case of CFPS reactions in the presence of $\mathrm{Ni}^{2+}$ or $\mathrm{Mn}^{2+}$, the quercetinase activity in the samples increased with increasing metal concentration in the reaction mixtures (except for the reaction that contained $3 \mathrm{mM} \mathrm{Ni}^{2+}$ ) (Additional file 4: Table S3). Unfortunately, zinc and copper ions had an inhibitory effect on the efficiency of QueD-EGFP synthesis
(Additional file 4: Figure S2 D-E), as also reported in CFPS studies on other metalloproteins [30,31]). The absence of quercetinase activity in the $\mathrm{Cu}^{2+}$ - and $\mathrm{Zn}^{2+}$-CFPS samples (Additional file 4: Table S3) suggested that $\mathrm{Cu}^{2+}$ and $\mathrm{Zn}^{2+}$ are either not incorporated into the QueDEGFP fusion protein, or do not support catalysis.

To purify (Strep-tagged) QueD proteins synthesized by CFPS, reactions were performed on a $1 \mathrm{ml}$ scale in the presence of $\mathrm{Ni}^{2+}, \mathrm{Mn}^{2+}$, or $\mathrm{Fe}^{2+/ 3+}$, or $\mathrm{Zn}^{2+}$ or $\mathrm{Cu}^{2+}$, and the proteins were prepared by Strep-Tactin affinity chromatography. The isolation of QueD proteins was verified in Western blots of denaturing polyacrylamide gels (Additional file 5: Figure S4). Far-UV CD spectra were recorded to find out whether the proteins synthesized in vitro have adopted the same overall fold as those produced in vivo (Figure 2). The spectrum of QueD produced in $\mathrm{Ni}^{2+}$-supplemented CFPS reactions retained the characteristics of that of the Ni-QueD formed in vivo, with a negative band at about $215 \mathrm{~nm}$ and a positive band at $198 \mathrm{~nm}$, indicating that QueD in the presence of nickel ions is able to fold to its native state in vitro. The protein produced in the presence of $1 \mathrm{mM} \mathrm{Mn}{ }^{2+}$ retained a high $\beta$-sheet content. In contrast, the CD spectra of the proteins obtained from CFPS in presence of $\mathrm{Cu}^{2+}(0.2 \mathrm{mM})$, $\mathrm{Zn}^{2+}(0.2 \mathrm{mM}), \mathrm{Fe}^{2+}$ or $\mathrm{Fe}^{3+}(1 \mathrm{mM})$ differ significantly from that of the nickel enzyme. Thus, the metal ions tested can be ordered as $\mathrm{Ni}>\mathrm{Mn}>>\mathrm{Zn}$, Fe, $\mathrm{Cu}$ according to their effect on secondary structure of QueD. Altogether, the findings suggest that while the efficiency of CFPS is similar in the presence of $\mathrm{Ni}^{2+}, \mathrm{Mn}^{2+}$ or $\mathrm{Fe}^{2+}$, in the in vitro situation only nickel ions support QueD folding to its native state.

QueD purified from CFPS reactions supplemented with $\mathrm{Ni}^{2+}$ and $\mathrm{Mn}^{2+}$ showed quercetinase activities of $21.3 \mathrm{U}$ $\mathrm{mg}^{-1}$ and 6.6 $\mathrm{U} \mathrm{mg}^{-1}$, respectively. For QueD isolated from CFPS-reactions supplemented with $\mathrm{Cu}^{2+}, \mathrm{Zn}^{2+}, \mathrm{Fe}^{2+}$ or $\mathrm{Fe}^{3+}$, the activity was approximately $0.1 \mathrm{U} \mathrm{mg}^{-1}$. Control experiments without metal ion supplementation indicated that such residual activity cannot be attributed to the supplemented metals, however, traces of $\mathrm{Mn}^{2+}$ and/or $\mathrm{Ni}^{2+}$ ions present in the E. coli extracts may confer activity to a subpopulation of the in vitro produced proteins. In terms of catalytic activity of QueD metal forms, we therefore obtain the ranking $\mathrm{Ni}>\mathrm{Mn}$. 


\section{Replacement of the $3 \mathrm{His} / 1 \mathrm{Glu}$ ligand amino acids of Ni-QueD}

To analyze the role of the metal-ligating amino acids for the structural integrity and function of $\mathrm{Ni}-\mathrm{QueD}$, the individual residues of the $3 \mathrm{His} / 1 \mathrm{Glu}$ motif (Figure 1) were replaced by site-directed mutagenesis, and the QueD proteins produced by the respective $E$. coli strain grown in $\mathrm{Ni}^{2+}$-supplemented medium were purified and characterized with respect to metal contents, catalytic activity, and ability to bind quercetin (Table 2). All variants, with the exception of the H69A substitution, showed a decrease in nickel contents compared to the wild-type protein, and a relative increase in the zinc contents pointing towards a somewhat relaxed metal specificity. The $K_{\mathrm{D}}$ values of the protein-quercetin complexes show that all protein variants retained a high affinity for the organic substrate. Replacement of the histidine residues at position 69 or 115 with alanine resulted in catalytically inactive protein variants, whereas the QueD-H71A and -E76D proteins retained marginal activity (Table 2). The CD spectra of the protein variants showed an increased intensity of the negative band (at approx. $215 \mathrm{~nm}$ ) and a hypsochromic (blue) shift of the positive band $(<200 \mathrm{~nm})$ compared to the wild type protein (Figure $3 \mathrm{~A}$ ). Thus, the loss of activity could be due to perturbation of the secondary structure.

Replacement of E76 by histidine resulted in a protein that showed about $2 \%$ of the activity of the wild-type protein and an about 8 -fold decreased $K_{\mathrm{D}}$ value compared to that of the quercetin complex with Ni-QueD (Table 2). Interestingly, the $\mathrm{CD}$ spectrum of the Ni-QueD-E76H protein was nearly superimposable to that of $\mathrm{Ni}-\mathrm{QueD}$ (Figure 3A), demonstrating that, in contrast to the other protein variants tested, the $\mathrm{E} 76 \mathrm{H}$ variant retained the wild-type conformation. This was also observed for the cobalt form of this protein (Figure $3 \mathrm{~B}$ ). To verify that the mutant protein catalyzes the same reaction as wild-type QueD, the organic products of quercetin conversion by Co-QueD and Co-QueD-E76H were extracted and subjected to LC/MS analysis. The LC elution profiles were identical and both showed a main peak at a retention time of $18.2 \mathrm{~min}$. ESI mass spectrometry of the corresponding peaks revealed ions at $\mathrm{m} / z 324.1$ $(100 \%)$ and $307.0(22 \%)$ for $\left[\mathrm{M}+\mathrm{NH}_{4}\right]^{+}$and $[\mathrm{M}+\mathrm{H}]^{+}$, respectively. This corresponds to the previously observed mass for the molecular ion of the product of quercetin conversion by recombinant $\mathrm{Ni}$ - and $\mathrm{Co}-\mathrm{QueD}$ and is consistent with formation of the depside 2protocatechuoylphloroglucinol carboxylic acid $\left(\mathrm{C}_{14} \mathrm{H}_{10} \mathrm{O}_{8}\right)$ [3]. The possibility that the same product could also result from a 2,3-dioxygenolytic side reaction to form an $\alpha$-oxo acid, and subsequent hydrolysis to formate and the depside, was examined by determining the concentration of formate in enzyme assays. Previous analysis of the reaction of ( His $_{6}$-tagged) $\mathrm{Ni}$ - and $\mathrm{Co}-\mathrm{QueD}$ had revealed an amount of formate corresponding to about $1.3 \%$ of the quercetin converted [3]. In the reaction of Strep-tagged Co-QueD, the formate detected corresponded to $2.3 \%$ $( \pm 0.2 \%)$ of substrate converted, whereas $3.0 \%( \pm 0.8 \%)$ of side product was observed in the reaction of the Co-QueD-E76H protein. Thus, both the wild-type and the mutant Co protein mediate this side reaction to a similar extent.

The observation that $\mathrm{Ni}$ - and Co-QueD-E76H were the only proteins in the series of variants that retained the wild-type fold may suggest that the metal ion is coordinated by four amino acid ligands in these variants, i.e., in a 4 His motif instead of the canonical $3 \mathrm{His} / 1 \mathrm{Glu}$ motif. The HSAB concept predicts a higher stability of the $\mathrm{Ni} / \mathrm{His}$ complex compared to a Ni/Glu complex, because the ligating nitrogen of His is softer than the ligating oxygen in Glu, leading to a larger stability of complexes with the soft $\mathrm{Ni}$ ion (or the $\mathrm{Co}$ ion). The $\mathrm{E} 76 \mathrm{H}$ variant shows an increase in affinity for its electron-rich organic substrate, indicated by the low $K_{\mathrm{D}}$ value (Table 2 ). This effect might be due to the altered charge distribution around the metal, since a carboxylate ligand (as in E76)

Table 2 Metal contents and activities of QueD proteins carrying ligand replacements, and $K_{D}$ values of protein-quercetin complexes

\begin{tabular}{llll}
\hline Protein $^{\mathbf{a}}$ & Metal content (equivalents per protein monomer) & Spec. activity $\left(\mathbf{U ~ m g}^{-\mathbf{1}}\right)$ & $\boldsymbol{K}_{\mathbf{D}}(\boldsymbol{\mu M})$ \\
\hline Ni-QueD-H69A & $0.88 \mathrm{Ni}, 0.07 \mathrm{Fe}$ & b.d. $^{\text {b }}$ & $3.1(0.9)$ \\
Ni-QueD-H115A & $0.34 \mathrm{Ni}, 0.29 \mathrm{Zn}, 0.07 \mathrm{Fe}, 0.02 \mathrm{Co}, 0.01 \mathrm{Mn}$ & b.d. & $2.6(0.6)$ \\
Ni-QueD-H71A & $0.18 \mathrm{Ni}, 0.16 \mathrm{Zn}, 0.06 \mathrm{Fe}$ & $0.90(0.04)$ & $10.4(2.9)$ \\
Ni-QueD-E76D & $0.28 \mathrm{Ni}, 0.24 \mathrm{Zn}, 0.05 \mathrm{Fe}$ & $1.32(0.01)$ & $4.0(1.0)$ \\
Ni-QueD-E76H & $0.54 \mathrm{Ni}, 0.03 \mathrm{Cu}, 0.02 \mathrm{Fe}, 0.01 \mathrm{Zn}$ & $3.44(0.13)$ & $1.3(0.1)$ \\
Co-QueD-E76H & $0.6 \mathrm{Co}, 0.03 \mathrm{Cu}, 0.02 \mathrm{Fe}, 0.01 \mathrm{Zn}, 0.02 \mathrm{Ni}$ & $0.19(0.01)$ & n.d. \\
\hline
\end{tabular}

${ }^{a}$ The designations of the QueD metal forms refer to the metal of interest and do not imply exclusive occupancy of the protein with this metal.

b.d., below detection.

cn.d., not determined.

Metal ions which contribute to $\geq 0.01$ equivalents per protein monomer are listed. For the specific activities and $K_{\mathrm{D}}$ values, the average of 3 experiments is given with the standard deviations in brackets. The $K_{\mathrm{D}}$ value of the complex of Ni-QueD with quercetin, determined for the preparation specified in Table 1 , was $10.1 \pm 2.9 \mu \mathrm{M}$. 


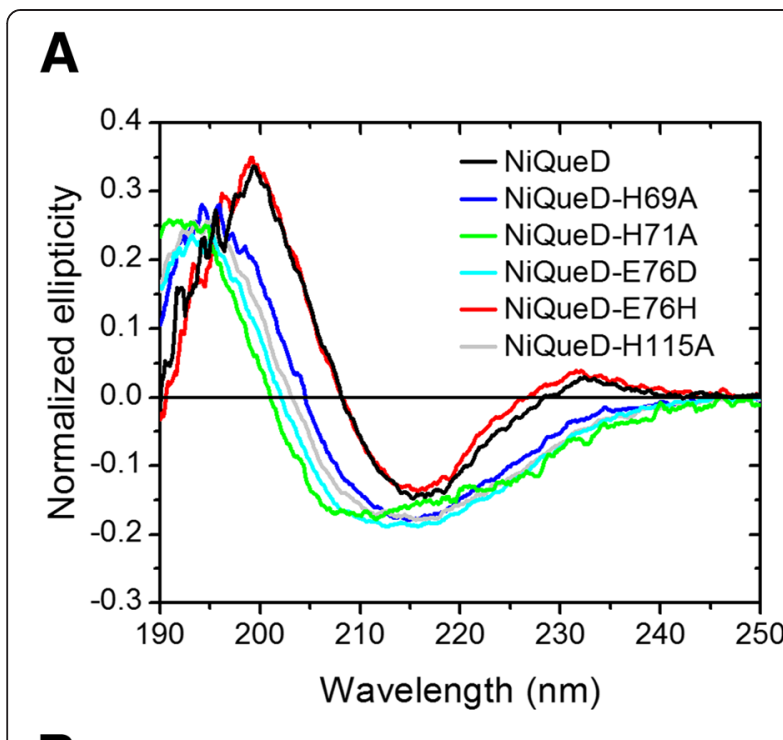

B

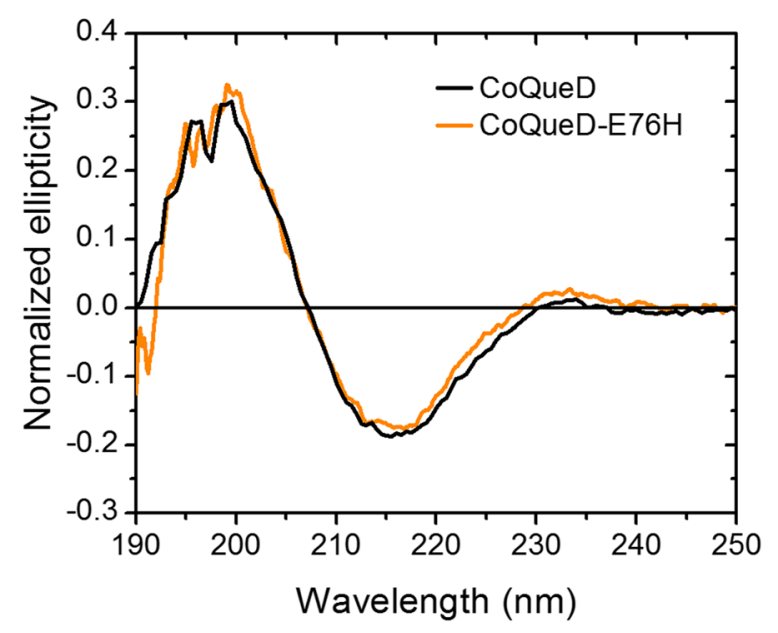

Figure 3 Far-UV CD spectra of QueD variants carrying amino acid replacements. (A), Ni-QueD proteins with amino acid substitutions in the $3 \mathrm{His} / 1 \mathrm{Glu}$ motif proposed to ligate the metal ion, and (B) Co-QueD with a substitution of the glutamate ligand by histidine. Protein samples in $10 \mathrm{mM}$ potassium phosphate buffer ( $\mathrm{pH}$ 8.0) were adjusted to $\sim 10 \mu \mathrm{M}$ (based on measuring absorbance at $280 \mathrm{~nm}$ ). Spectra were recorded at $25^{\circ} \mathrm{C}$ in a $1 \mathrm{~mm}$ path length cell; bandwidth: $0.1 \mathrm{~nm}$.

transfers more charge to the metal ion than an imidazole nitrogen. Alternatively, or additionally, subtle rearrangements of all the ligands around the metal may account for the decrease of the $K_{\mathrm{D}}$ value of Ni-QueD-E76H compared to that of the Ni-QueD-quercetin complex.

\section{Discussion}

Bacterial quercetinases have been described to be able to use a defined set of different metal ions for catalysis, but the molecular basis of such metal selection is largely unclear. When using a recombinant high-expression system in E. coli for the production of Streptomyces QueD, the metal contents of the purified proteins suggested that QueD binds $\mathrm{Mn}^{2+}, \mathrm{Fe}^{2+}, \mathrm{Co}^{2+}$, and $\mathrm{Ni}^{2+}$ in the order $\mathrm{Mn}<\mathrm{Fe}<\mathrm{Co} \approx \mathrm{Ni}$. This ranking is similar to the IrvingWilliams series, which describes the stability of divalent transition-metal complexes as $\mathrm{Mn}^{2+}<\mathrm{Fe}^{2+}<\mathrm{Co}^{2+}$ $<\mathrm{Ni}^{2+}<\mathrm{Cu}^{2+}>\mathrm{Zn}^{2+}$ [32]. Interestingly, QueD purified from the wild-type Streptomyces sp. strain contained mainly nickel and zinc. However, quantitative metal analyses cannot distinguish between metal ions unspecifically adsorbed to the protein surface or those coordinated to the conserved metal-binding $3 \mathrm{His} / 1 \mathrm{Glu}$ motif of the cupin protein.

Because the concentrations of "free" transition metal ions are thought to be in the $10^{-7}$ to $10^{-15} \mathrm{M}$ range $[33,34]$, metal incorporation into QueD in the E. coli expression system may be limited by metal ion availability. In contrast, the cell-free transcription-translation system allows for supplementation with defined metal ion concentrations. To outcompete divalent ions possibly brought in by the highly concentrated $E$. coli extracts used in the CFPS reactions, we added metal ions in excess, at concentrations which still supported protein synthesis ( $c f$. Additional file 4). The CD spectra and activity data of the QueD forms produced in vitro indicated that intrinsic properties of the protein rather than metal ion availability govern the formation of native metalloenzyme, with $\mathrm{Ni}^{2+}$ as the strongly preferred ion.

The coordination geometry of the metal center should play a significant role in determining the preference of QueD for its active-site ion. $\mathrm{Ni}^{2+}$ centers with metal binding by a $3 \mathrm{His} / 1 \mathrm{Glu}$ motif show a preference for octahedral geometry $[35,36] . \mathrm{Co}^{2+}$ and $\mathrm{Mn}^{2+}$ centers are usually also hexa-coordinated with an octahedral geometry [37]. $\mathrm{Zn}^{2+}$ typically has coordination numbers of four or five in active sites of enzymes, with a preference for tetrahedral geometry [37]. $\mathrm{Cu}^{2+}$ bound to proteins is typically coordinated by four ligands in a square planar geometry [37,38], or with an additional water ligand positioned to form a trigonal bipyramidal geometry [39]. $\mathrm{Fe}^{2+}$ complexes in proteins are either penta- or hexa-coordinated, with pentacoordination as most common [40]. Possibly, formation of native, catalytically competent (Ni-, Co-, Mn-) QueD correlates with the propensity of the metal ions to form an octahedral complex geometry, as dictated by the ligands that constitute the metal binding site of the protein. If so, the metal center of Streptomyces QueD would comprise two additional ligands (such as water molecules) besides the four amino acid ligands and thus would be different from that of copper-dependent $A$. japonicus quercetinase, which shows a penta-coordinated metal center with 3 His, $1 \mathrm{Glu}$ and one water molecule [1]. Interestingly, an octahedral coordination sphere was also proposed for the catalytically highly active Mn-QueD of B. subtilis [17], 
whereas its less active Fe-form, which has been crystallized, is penta-coordinate with a square pyramidal or distorted trigonal bipyramidal geometry [2]. Thus, the geometry of the nickel center of Streptomyces QueD may be different from that shown in Figure 1 which is based on homology modelling using the crystal structure of quercetinase of $B$. subtilis as template.

The CD spectra of QueD proteins carrying replacements of individual residues of the 3His/1Glu motif suggested that all four residues are important for structural integrity of QueD, although Glu76 can be exchanged to histidine without affecting the secondary structure of the protein. The important structural role of both metal and ligands in QueD is in contrast to several other cupin proteins, which tolerate the substitution of individual metalcoordinating amino acid residues or which even retain their structure upon in vitro metal depletion $[26,41,42]$.

\section{Conclusions}

Streptomyces quercetinase (QueD), a metal dependent flavonol dioxygenase with a cupin fold, is rather promiscuous with respect to the incorporated metal ion. This study shows that QueD produced in a heterologous host requires $\mathrm{Ni}^{2+}, \mathrm{Co}^{2+}$ or $\mathrm{Mn}^{2+}$, i.e. metal ions that prefer an octahedral coordination geometry, for native secondary structure content and catalytic activity. $\mathrm{Ni}^{2+}$ ions support the formation of native QueD in a cell-free transcription/ translation system. The in vivo and in vitro data suggest that metal ion specificity of QueD is determined by both chemical stability (the Irving-Williams series) and intrinsic geometric constraints dictated by the metalloprotein. Taking all criteria together, $\mathrm{Ni}$ appears to be the physiologically optimal ion for Streptomyces quercetinase. Crystal structures of QueD, as well as of QueD-E76H protein and enzyme-substrate complexes, would be most interesting to compare this bacterial quercetinase to the fungal copper quercetinase with atomic resolution.

\section{Methods}

Research performed in this study does not involve human subjects, human material, or human data.

\section{Materials}

Chemicals were purchased from Sigma-Aldrich, except for tRNAs from E. coli strain MRE 600 which were obtained from Roche Applied Science. Restriction enzymes, T4 DNA ligase, and other reagents for molecular biology were purchased from Thermo Scientific. DNA primers, listed in Table 3, were obtained from Microsynth AG (Balgach, Switzerland) or MWG Biotech AG (Ebersberg, Germany).

\section{DNA techniques}

Isolation of plasmid DNA from recombinant E. coli strains, extraction of DNA fragments from agarose gels, and purification of PCR products were carried out by the innuPREP kit series (Analytik Jena AG, Jena, Germany). Standard protocols were used for agarose gel electrophoresis, restriction digestion, and DNA ligation. Exchange of the $\mathrm{His}_{6}$-tag sequence in pET23a-queD [10] for a StrepIItag sequence was performed by amplification of the plasmid with the primer pair strepfor/streprev (Table 3), restriction with DpnI and NotI, and circularisation with T4 DNA ligase. For fusion of enhanced green fluorescent protein to QueD, the egfp gene was amplified by PCR,

Table 3 Oligonucleotides used for gene amplification and site-directed mutagenesis

\begin{tabular}{|c|c|c|}
\hline Name & Nucleotide sequence $\left(5^{\prime} \rightarrow 3^{\prime}\right)$ & Application \\
\hline quedfor & TGACCATCGAATACGCCACCCGTCACC & Amplification of queD \\
\hline quedrev & GACGTCGTACTGCTCGGGCACGGTC & \\
\hline strepfor & $\begin{array}{l}\text { ATAAGAATGCGGCCGCATTAGAATGGAGCCACCCGCAGTTCGAAAAA } \\
\text { TGAGATCCGGCTGCTAACAAAGCCCGAAAGG }\end{array}$ & Exchange of $\mathrm{His}_{6}$-tag for Strepll-tag \\
\hline streprev & ATAAGAATGCGGCCGCAAGCTTCCTTCCCTCGATACTCCCGGTGTGC & \\
\hline gfpfor & TATAAGCTTGCCGGTGCGGAAAATC & Amplification of the EGFP gene \\
\hline gfprev & TATAGCGGCCGCCTGGTACAGTTCATCCATG & \\
\hline H69Afor & CCTCGCACGCGGACACCTACG & Exchange of His69 for Ala \\
\hline H69Arev & CGGCGGGGATCACCTCGCCCTTG & \\
\hline H71Afor & CGCCCACTCGGCCGCGGACACCTACGAGGTCTTC & Exchange of His71 for Ala \\
\hline H71Arev & GGGATCACCTCGCCCTTGGGGCCCTCGCAG & \\
\hline H115Afor & ATGGAACGCCACCACTCGCAGGTCG & Exchange of His115 for Ala \\
\hline H115Arev & GCGGTAGGCGGCCACGCAGTTCTCGGTACGAAGC & \\
\hline E76Hfor/E76Dfor & CGTCTTCTACATCACCCAGGGC & Forward primer for the exchange of Glu76 for His or Asp \\
\hline E76Hrev & TGGTAGGTGTCCGCGTGCGAGTGG & Reverse primer for the exchange of Glu76 for His \\
\hline E76Drev & TCGTAGGTGTCCGCGTGCGAG & Reverse primer for the exchange of Glu76 for Asp \\
\hline
\end{tabular}

Recognition sites for restriction endonucleases are italicized. 
using the primer pair gfpfor/gfprev (Table 3), and plasmid pET27b-egfp harboring a synthetic gene (GenScript) for EGFP (F64L/S65T/Q80R/K238Q) as template. The PCR product and pET23a-queD-Strep were restricted with HindIII and NotI, purified with the innuPREP Doublepure kit (Analytik Jena AG), and ligated, resulting in pET23aqueD-egfp-Strep. Transformation of E. coli strains DH5a and BL21 (DE3) [pLysS] with the constructed plasmid was performed as described by Hanahan [43]. Site-directed mutagenesis of the queD gene (GenBank accession number AM234612) was performed according to the protocol of the Phusion ${ }^{\text {Tw }}$ Site-Directed Mutagenesis Kit (Thermo Scientific) using pET23a-queD-Strep as template, Phusion ${ }^{\text {Tu }}$ High-Fidelity DNA polymerase for amplification, and the primers listed in Table 3. Confirmatory DNA sequencing of the insert and flanking regions of the plasmids was performed by GATC Biotech AG (Konstanz, Germany) or MWG Biotech AG.

\section{Cell-free protein synthesis (CFPS)}

Cell-free protein synthesis was conducted at $30^{\circ} \mathrm{C}$ using the PANOx-SP system [44], except that instead of S30 cell extract, S12 extract from E. coli strain BL21 (DE3) was used, which was prepared as described by Kim et al. [45]. Crude extract of E. coli strain BL21 (DE3) containing T7 RNA polymerase was prepared separately as described in ref. [44]. In order to quantify the relative amounts of protein produced by CFPS, the plasmid pET23a-queD-egfp-Strep was used as template for in vitro transcription-translation reactions supplemented with metal salts $(0.05-3 \mathrm{mM})$. The relative amount of EGFP present in the samples (as QueD-EGFP fusion) was determined by measuring the average fluorescence emission at 510 $570 \mathrm{~nm}$ upon excitation at $490 \mathrm{~nm}$. Cell-free synthesis of QueD-Strep, using pET23a-queD-Strep as template, was performed in the presence of $1 \mathrm{mM} \mathrm{NiCl} 2,1 \mathrm{mM} \mathrm{MnCl}$, $0.5 \mathrm{mM} \mathrm{FeCl}_{2}$ or $1 \mathrm{mM}\left(\mathrm{NH}_{4}\right)_{2} \mathrm{Fe}\left(\mathrm{SO}_{4}\right)_{2}$ (optionally supplemented with $1 \mathrm{mM}$ DTT), $1 \mathrm{mM} \mathrm{FeCl}, 1 \mathrm{mM}$ or $0.2 \mathrm{mM} \mathrm{CuCl}_{2}$, and $1 \mathrm{mM}$ or $0.2 \mathrm{mM} \mathrm{ZnCl}_{2}$.

\section{Expression and purification of C-terminally Strep-tagged QueD proteins}

E. coli BL21 (DE3) [pLysS, pET23a-queD-Strep] as well as E. coli strains containing a mutant pET23a-queD-Strep plasmid were grown at $37^{\circ} \mathrm{C}$ to an $\mathrm{OD}_{600}$ of 0.5 in M9 minimal medium [46] containing ampicillin $\left(100 \mu \mathrm{g} \mathrm{ml}^{-1}\right)$ and chloramphenicol $\left(34 \mu \mathrm{g} \mathrm{ml}^{-1}\right)$. Subsequently, metal salts $\left(\mathrm{MnCl}_{2}, \mathrm{FeCl}_{2}, \mathrm{CoCl}_{2}, \mathrm{NiCl}_{2}\right.$, or $\left.\mathrm{ZnCl}_{2}\right)$ were added to the cultures to final concentrations of $10 \mu \mathrm{M}$ (in case of $\mathrm{Ni}^{2+}$ and $\mathrm{Co}^{2+}$ ), $30 \mu \mathrm{M}$ (for $\mathrm{Mn}^{2+}, \mathrm{Fe}^{2+}$, and $\mathrm{Zn}^{2+}$ ) or $1 \mathrm{mM}$ (for $\mathrm{Mn}^{2+}$ ), and expression of queD was induced with $1 \mathrm{mM}$ IPTG. The cultivation temperature was reduced to $25^{\circ} \mathrm{C}$ for $3 \mathrm{~h}$ and then shifted to $20^{\circ} \mathrm{C}$ for another $15 \mathrm{~h}$. The cells were centrifuged $\left(4^{\circ} \mathrm{C}, 10 \mathrm{~min}\right.$ at $\left.12,000 \times g\right)$ and the cell pellets were stored at $-80^{\circ} \mathrm{C}$. For the preparation of cell extracts, cells were resuspended in $100 \mathrm{mM}$ Tris/ $\mathrm{HCl}$ buffer (pH 8) containing $300 \mathrm{mM} \mathrm{NaCl}$ and $1 \mathrm{mM}$ $\mathrm{MgCl}_{2}$, supplemented with 12.5 units of Benzonase (Novagen). After incubation on ice for $1 \mathrm{~h}$, the suspension was sonicated and then centrifuged $\left(4^{\circ} \mathrm{C}, 40 \mathrm{~min}\right.$ at $\left.38,360 \times \mathrm{g}\right)$. Recombinant QueD proteins were purified from cell extract supernatant by affinity chromatography on a $2 \mathrm{ml}$ Strep-Tactin ${ }^{\circledR}$ column (IBA, Göttingen, Germany) using an FPLC system. QueD proteins synthesized by in vitro transcription/translation were isolated using a $0.5 \mathrm{ml}$ StrepTactin $^{\circ}$ gravity column. After removing unbound proteins with $100 \mathrm{mM}$ Tris/ $\mathrm{HCl}$ buffer $(\mathrm{pH}$ 8.0) containing $300 \mathrm{mM} \mathrm{NaCl}$, Strep-tagII fusion proteins were eluted with $2.5 \mathrm{mM}$ desthiobiotin in the same buffer. Fractions containing the protein of interest were pooled, concentrated by ultrafiltration in a Vivaspin 20 concentrator (Sartorius Stedim Biotech), frozen in liquid nitrogen and stored at $-80^{\circ} \mathrm{C}$.

\section{Growth of Streptomyces sp. FLA and purification of QueD protein}

Growth of Streptomyces sp. strain FLA in complex medium, followed by resuspension of the biomass in mineral salts medium supplemented with quercetin, was performed as described previously [10]. The growth medium contains ammonium ferric citrate $(1 \mu \mathrm{M})$ and $100 \mu \mathrm{l} / \mathrm{l}$ of SL-6 trace element solution according to Pfennig [47], resulting in final concentrations of $\mathrm{Cu}^{2+}$, $\mathrm{Ni}^{2+}, \mathrm{Mn}^{2+}, \mathrm{Zn}^{2+}$ and $\mathrm{Co}^{2+}$ salts of $0.6 \mathrm{nM}, 0.8 \mathrm{nM}, 1.5$ $\mathrm{nM}, 3.5 \mathrm{nM}$, and $8.4 \mathrm{nM}$, respectively. For the preparation of cell extracts, Streptomyces biomass was suspended in $50 \mathrm{mM}$ Tris/ $\mathrm{HCl}$ buffer (pH 7.0) and disrupted by sonication. After a centrifugation step $(38,360 \times g, 90 \mathrm{~min})$ to remove cell debris, $\left(\mathrm{NH}_{4}\right)_{2} \mathrm{SO}_{4}$ was gradually added to the cell extract supernatant to a final concentration of $0.4 \mathrm{M}$, and precipitated proteins were removed by centrifugation at $38,360 \times g$ for 40 minutes at $4^{\circ} \mathrm{C}$. The supernatant was applied to a $20 \mathrm{ml}$ Phenyl-Sepharose CL-4B column (GE Healthcare) that was equilibrated in $50 \mathrm{mM}$ Tris/HCl, $\mathrm{pH}$ 7.0, containing 0.4 $\mathrm{M}\left(\mathrm{NH}_{4}\right)_{2} \mathrm{SO}_{4}$. Quercetinase was eluted by stepwise reducing the concentration of $\left(\mathrm{NH}_{4}\right)_{2} \mathrm{SO}_{4}(0.4$ to $0 \mathrm{M})$ in the buffer. The protein fractions with quercetinase activity were pooled and dialyzed against $50 \mathrm{mM}$ Tris/HCl buffer $(\mathrm{pH}$ 8.0). The protein pool was applied to a $6 \mathrm{ml}$ Q Sepharose Fast Flow column (GE Healthcare) equilibrated in $50 \mathrm{mM}$ Tris/ $\mathrm{HCl}$ buffer $(\mathrm{pH} 8)$. Protein fractions with quercetinase activity were eluted with $0.3 \mathrm{M} \mathrm{NaCl}$ and dialyzed as described above. A second anion exchange step was performed on a $2 \mathrm{ml}$ Source 15Q (GE Healthcare) column. Quercetinase was eluted with $0.2 \mathrm{M} \mathrm{NaCl}$, concentrated by ultrafiltration, and stored in $50 \mathrm{mM}$ Tris/HC $(\mathrm{pH} 8)$ at $-80^{\circ} \mathrm{C}$. 


\section{Protein analysis}

Molecular graphics was performed with the UCSF Chimera package, developed by the Resource for Biocomputing, Visualization, and Informatics at the University of California, San Francisco (supported by NIGMS P41GM103311) [48]. Protein concentrations in cell-free extracts and CFPS reactions were estimated using the Bradford method as modified by Zor and Selinger [49]. Concentrations of electrophoretically pure QueD-Strep proteins were estimated from their absorbance at $280 \mathrm{~nm}$, using the theoretical molar extinction coefficient of $\varepsilon_{280 \mathrm{~nm}}=21,555 \mathrm{M}^{-1} \mathrm{~cm}^{-1}$, calculated according to Pace et al. [50]. Metal contents of QueD preparations and buffer blanks were determined by inductively coupled plasma optical emission spectroscopy (ICP-OES), or by ICP-MS, performed by the Chemical Analysis Laboratory, Center for Applied Isotope Studies, University of Georgia (Athens, GA, USA). To prepare samples for metal analysis, the proteins were washed 3 times with 10-fold volumes of $50 \mathrm{mM}$ Tris/HCl buffer ( $\mathrm{pH} 8.0$ ). Before use, the buffer was treated with Serdolit $^{\oplus}$ Chelite $^{\oplus}$ CHE (SERVA Electrophoresis, Heidelberg, Germany) to remove divalent cations. QueD activity was determined spectrophotometrically at $30^{\circ} \mathrm{C}$ by measuring quercetin consumption as described previously [3]. One unit (U) of QueD is defined as the amount of enzyme that catalyzes the conversion of $1 \mu \mathrm{mol}$ of quercetin per minute at $30^{\circ} \mathrm{C}$. Assays for the determination of apparent steady-state parameters of QueD for quercetin were performed in air-saturated buffer (50 mM Tris/HCl, pH 8.0) [3].

\section{Identification of organic reaction products}

Samples for identifying the organic products of quercetin conversion by Co-QueD-E76H and Co-QueD were prepared and extracted as described previously [3]. LC/MS analysis of the extracts was performed on a Dionex $^{\mathrm{TM}}$ Ultimate $^{\mathrm{TM}} 3000$ UHPLC system (Thermo Scientific), coupled to an amaZon speed ion trap mass spectrometer (Bruker). Products were separated with an Eurospher II 100-5 C18 column (Knauer GmbH, Berlin, Germany), using a linear gradient of $20 \%$ to $100 \%$ (over $45 \mathrm{~min}$ ) methanol in $10 \mathrm{mM}$ aqueous ammonium acetate, adjusted to $\mathrm{pH} 4.0$ with acidic acid, at a flow rate of $0.4 \mathrm{ml} \mathrm{min}^{-1}$.

To analyze whether formate is formed from quercetin in a possible side reaction, $0.1 \mathrm{U} \mathrm{ml}^{-1}$ of Co-QueD or Co-QueD-E76H were incubated with $200 \mu \mathrm{M}$ quercetin in $20 \mathrm{mM}$ potassium phosphate buffer ( $\mathrm{pH}$ 7.0) for 90 min. Subsequently, Candida boidinii formate dehydrogenase (Fluka, $50 \mathrm{U} \mathrm{ml}^{-1}$ ) and $\mathrm{NAD}^{+}(40 \mathrm{mM})$ were added to final concentrations of $0.5 \mathrm{U} \mathrm{ml}^{-1}$ and $2 \mathrm{mM}$, respectively. Formation of NADH was monitored at $340 \mathrm{~nm}$ over $180 \mathrm{~min}$. $\mathrm{NAD}^{+}$solutions were always prepared freshly in $20 \mathrm{mM}$ phosphate buffer ( $\mathrm{pH}$ 7.0). For background correction, reference samples without formate dehydrogenase containing the QueD-quercetin reaction mixtures and $\mathrm{NAD}^{+}$were monitored as well. Under these assay conditions, the detection limit of formic acid is in the $\mu \mathrm{M}$ range: $10 \mu \mathrm{M}$ and $1 \mu \mathrm{M}$ formic acid were detected with percentage deviations of $\pm 12 \%$ and $\pm 77 \%$, respectively.

\section{Fluorescence titration}

Dissociation constants $K_{\mathrm{D}}$ of enzyme-quercetin complexes were determined by fluorescence titrations, measuring intrinsic protein fluorescence in a Jasco FP-6500 spectrofluorometer. In an anaerobic glove box, degassed anoxic solutions of QueD protein were diluted in an anaerobic cuvette with $\mathrm{N}_{2}$-saturated buffer (50 mM Tris/ $\mathrm{HCl}, \mathrm{pH}$ 8.0, treated with Serdolit ${ }^{\oplus}$ Chelite $\left.^{\circledR} \mathrm{CHE}\right)$ to a final concentration of approximately $1 \mu \mathrm{M}$. Small amounts of anoxic quercetin solution were added stepwise, mixed gently, and allowed to equilibrate at $30^{\circ} \mathrm{C}$ for $15-20 \mathrm{mi}-$ nutes. Upon excitation at $280 \mathrm{~nm}$, the fluorescence intensities at $\lambda_{\max }=340 \mathrm{~nm}$ were recorded after each titration step and plotted against the quercetin concentration. $K_{\mathrm{D}}$ values were determined from analysis of binding curves using the equation for a quadratic binding curve [51].

\section{Circular Dichroism (CD) spectroscopy}

Far-UV CD spectra of proteins were recorded from 190 to $250 \mathrm{~nm}$ at $25^{\circ} \mathrm{C}$ with a J-815 circular dichroism spectrometer (Jasco), using a $0.1-\mathrm{cm}$ path length cell, with a digital time integration of $1 \mathrm{~s}$ and a scan speed of $50-100 \mathrm{~nm} /$ min. Spectra were accumulated 7 -10-fold. Protein samples were in $10 \mathrm{mM}$ potassium phosphate buffer ( $\mathrm{pH} 8.0$ ). The protein concentration in the cuvette was adjusted to a final concentration of $\sim 10 \mu \mathrm{M}$. All protein spectra were corrected by subtracting the CD spectrum of the buffer. To correct for errors such as slight differences in protein concentrations, spectra were scaled by normalizing each spectrum by $\|\Theta\|=\left(\int \Theta(\lambda)^{2} \mathrm{~d} \lambda\right)^{1 / 2}[52]$.

\section{Additional files}

Additional file 1: Figure S1. Electrophoretic analysis of QueD proteins. Additional file 2: Table S1. Metal-related catalytic activity of QueD. Additional file 3: Table S2. Purification of QueD from Streptomyces sp. FLA.

Additional file 4: Figure $\mathbf{S 2}$ and Table S3. Production of QueD-EGFP fusion protein by cell-free protein synthesis (CFPS), and quercetinase activity of QueD-EGFP in the CFPS reactions.

Additional file 5: Figure S4. Verification of QueD synthesis by the CFPS system.

\section{Abbreviations}

CD: Circular dichroism; CFPS: Cell-free protein synthesis; DTT: Dithiothreitol; FPLC: Fast protein liquid chromatography; HSAB: Hard-soft acids and bases; ICP-MS: Inductively coupled plasma mass spectroscopy; ICP-OES: Inductively coupled plasma optical emission spectroscopy; IPTG: Isopropyl- $\beta$-D-

thiogalactopyranoside; LB: Lysogeny broth; LC/MS: Liquid chromatography 
coupled with mass spectroscopy; NADH: Nicotinamide adenine dinucleotide; QueD: Quercetinase of Streptomyces sp. FLA; U: Enzyme units; UV: Ultraviolet.

\section{Competing interests}

The authors declare that they have no competing interests.

\section{Authors' contributions}

DN carried out the molecular genetic experiments, the cell-free synthesis of QueD, and characterized the biochemical properties of the QueD variants. ST identified the organic products of the reaction catalyzed by QueD, and performed statistical analyses of data. DN, LS and PL designed and performed circular dichroism experiments. PL and DK analyzed CD data. DK contributed to manuscript writing. SF conceived of the study and wrote the manuscript draft. All authors contributed to the final version of the manuscript, and all authors read and approved the final manuscript.

\section{Acknowledgments}

We thank Prof. Dr. Simone König (Integrated Functional Genomics, University of Münster, Germany) for MALDI-MS analysis. We also thank Steffen Drees for the synthetic EGFP template and Almut Kappius for expert technical assistance. This work was supported by the Deutsche Forschungsgemeinschaft (grant no. FE 383/18-1 to S.F.). We also acknowledge support by the Open Access Publication Fund of University of Münster.

\section{Author details}

${ }^{1}$ Institute of Molecular Microbiology and Biotechnology, University of Muenster, Corrensstrasse 3, Muenster D-48149, Germany. Institute of Physical Chemistry, University of Muenster, Corrensstrasse 30, Muenster D-48149, Germany.

Received: 1 December 2014 Accepted: 1 April 2015 Published online: 23 April 2015

\section{References}

1. Fusetti F, Schröter $\mathrm{KH}$, Steiner RA, van Noort PI, Pijning T, Rozeboom HJ, et al. Crystal structure of the copper-containing quercetin 2,3-dioxygenase from Aspergillus japonicus. Structure. 2002;10:259-68.

2. Gopal B, Madan LL, Betz SF, Kossiakoff AA. The crystal structure of a quercetin 2,3-dioxygenase from Bacillus subtilis suggests modulation of enzyme activity by a change in the metal ion at the active site(s). Biochemistry. 2005:44:193-201.

3. Merkens H, Kappl R, Jakob RP, Schmid FX, Fetzner S. Quercetinase QueD of Streptomyces sp. FLA, a monocupin dioxygenase with a preference for nickel and cobalt. Biochemistry. 2008;47:12185-96.

4. Tranchimand S, Ertel G, Gaydou V, Gaudin C, Tron T, lacazio G. Biochemical and molecular characterization of a quercetinase from Penicillium olsonii. Biochimie. 2008:90:781-9.

5. Dunwell JM, Purvis A, Khuri S. Cupins: the most functionally diverse protein superfamily? Phytochemistry. 2004;65:7-17.

6. Steiner RA, Kalk KH, Dijkstra BW. Anaerobic enzyme-substrate structures provide insight into the reaction mechanism of the copper-dependent quercetin 2,3-dioxygenase. Proc Natl Acad Sci U S A. 2002;99:16625-30.

7. Kooter IM, Steiner RA, Dijkstra BW, van Noort PI, Egmond MR, Huber M. EPR characterization of the mononuclear Cu-containing Aspergillus japonicus quercetin 2,3-dioxygenase reveals dramatic changes upon anaerobic binding of substrates. Eur J Biochem. 2002;269:2971-9.

8. Steiner RA, Kooter IM, Dijkstra BW. Functional analysis of the copper-dependent quercetin 2,3-dioxygenase. 1. Ligand-induced coordination changes probed by X-ray crystallography: inhibition, ordering effect, and mechanistic insights. Biochemistry. 2002;41:7955-62.

9. Steiner RA, Meyer Klaucke W, Dijkstra BW. Functional analysis of the copper-dependent quercetin 2,3-dioxygenase. 2. X-ray absorption studies of native enzyme and anaerobic complexes with the substrates quercetin and myricetin. Biochemistry. 2002;41:7963-8.

10. Merkens H, Sielker S, Rose K, Fetzner S. A new monocupin quercetinase of Streptomyces sp. FLA: identification and heterologous expression of the queD gene and activity of the recombinant enzyme towards different flavonols. Arch Microbiol. 2007;187:475-87.

11. Bugg TDH. Dioxygenase enzymes: catalytic mechanisms and chemical models. Tetrahedron. 2003;59:7075-101.
12. Oka T, Simpson FJ. Quercetinase, a dioxygenase containing copper. Biochem Biophys Res Commun. 1971;43:1-5.

13. Oka T, Simpson FJ, Krishnamurty HG. Degradation of rutin by Aspergillus flavus. Studies on specificity, inhibition, and possible reaction mechanism of quercetinase. Can J Microbiol. 1972;18:493-508.

14. Hund HK, Breuer J, Lingens F, Hüttermann J, Kappl R, Fetzner S. Flavonol 2,4-dioxygenase from Aspergillus niger DSM 821, a type 2 Cull-containing glycoprotein. Eur J Biochem. 1999;263:871-8.

15. Barney BM, Schaab MR, LoBrutto R, Francisco WA. Evidence for a new metal in a known active site: purification and characterization of an iron-containing quercetin 2,3-dioxygenase from Bacillus subtilis. Protein Expr Purif. 2004;35:131-41.

16. Bowater L, Fairhurst SA, Just VJ, Bornemann S. Bacillus subtilis YxaG is a novel Fe-containing quercetin 2,3-dioxygenase. FEBS Lett. 2004;557:45-8.

17. Schaab MR, Barney BM, Francisco WA. Kinetic and spectroscopic studies on the quercetin 2,3-dioxygenase from Bacillus subtilis. Biochemistry. 2006:45:1009-16

18. Boer JL, Mulrooney SB, Hausinger RP. Nickel-dependent metalloenzymes. Arch Biochem Biophys. 2013;544:142-52.

19. Merkens $H$, Fetzner $\mathrm{S}$. Transcriptional analysis of the queD gene coding for quercetinase of Streptomyces sp. FLA. FEMS Microbiol Lett. 2008;287:100-7.

20. Mirzoewa OK, Grishanin RN, Calder PC. Antimicrobial action of propolis and some of its components: the effects on growth, membrane potential and motility of bacteria. Microbiol Res. 1997;152:239-46.

21. Plaper A, Golob M, Hafner I, Oblak M, Solmajer T, Jerala R. Characterization of quercetin binding site on DNA gyrase. Biochem Biophys Res Commun. 2003;306:530-6.

22. Wu D, Kong $Y$, Han C, Chen J, Hu L, Jiang H, et al. D-Alanine:D-alanine ligase as a new target for the flavonoids quercetin and apigenin. Int J Antimicrob Agents. 2008:32:421-6.

23. Cushnie TPT, Lamb AJ. Recent advances in understanding the antibacterial properties of flavonoids. Int J Antimicrob Agents. 2011;38:99-107.

24. Hosny M, Dhar K, Rosazza JPN. Hydroxylations and methylations of quercetin, fiestin, and catechin by Streptomyces griseus. J Nat Prod. 2001;64:462-5

25. Ma B, Zeng J, Shao L, Zhan J. Efficient bioconversion of quercetin into a novel glycoside by Streptomyces rimosus subsp. rimosus ATCC 10970. J Biosci Bioeng. 2013;115:24-6.

26. Moomaw EW, Angerhofer A, Moussatche P, Ozarowski A, García-Rubio I, Richards NGJ. Metal dependence of oxalate decarboxylase activity. Biochemistry. 2009;48:6116-25.

27. Miyazaki-Imamura C, Oohira K, Kitagawa R, Nakano H, Yamane T, Takahashi $\mathrm{H}$. Improvement of $\mathrm{H}_{2} \mathrm{O}_{2}$ stability of manganese peroxidase by combinatorial mutagenesis and high-throughput screening using in vitro expression with protein disulfide isomerase. Protein Eng. 2003;16:423-8.

28. Boyer ME, Wang CW, Swartz JR. Simultaneous expression and maturation of the iron-sulfur protein ferredoxin in a cell-free system. Biotechnol Bioeng. 2006;94:128-38.

29. Boyer ME, Stapleton JA, Kuchenreuther JM, Wang CW, Swartz JR. Cell-free synthesis and maturation of [FeFe] hydrogenases. Biotechnol Bioeng. 2008;99:59-67.

30. Ezure T, Suzuki T, Ando E, Nishimura O, Tsunasawa S. Expression of human $\mathrm{Cu}, \mathrm{Zn}$-superoxide dismutase in an insect cell-free system and its structural analysis by MALDI-TOF MS. J Biotechnol. 2009;144:287-92.

31. Matsuda T, Kigawa T, Koshiba S, Inoue M, Aoki M, Yamasaki K, et al. Cell-free synthesis of zinc-binding proteins. J Struct Funct Genomics. 2006;7:93-100.

32. Irving H, Williams RJP. The stability of transition-metal complexes. J Chem Soc. 1953;3192-210. doi:10.1039/jr9530003192.

33. Outten CE, O'Halloran TV. Femtomolar sensitivity of metalloregulatory proteins controlling zinc homeostasis. Science. 2001;292:2488-92.

34. Williams RJP. Chemical selection of elements by cells. Coord Chem Rev. 2001;216-217:583-95.

35. He MM, Clugston SL, Honek JF, Matthews BW. Determination of the structure of Escherichia coli glyoxalase I suggests a structural basis for differential metal activation. Biochemistry. 2000;39:8719-27.

36. Chai SC, Ju TT, Dang M, Goldsmith RB, Maroney MJ, Pochapsky TC. Characterization of metal binding in the active sites of acireductone dioxygenase isoforms from Klebsiella ATCC 8724. Biochemistry. 2008;47:2428-38

37. Dudev T, Lim C. Competition among metal ions for protein binding sites: determinants of metal ion selectivity in proteins. Chem Rev. 2014;114:538-56. 
38. Rulišek $L$, Vondrášek J. Coordination geometries of selected transition metal ions $\left(\mathrm{Co}^{2+}, \mathrm{Ni}^{2+}, \mathrm{Cu}^{2+}, \mathrm{Zn}^{2+}, \mathrm{Cd}^{2+}\right.$, and $\left.\mathrm{Hg}^{2+}\right)$ in metalloproteins. J Inorg Biochem. 1998;71:115-27

39. McCall KA, Fierke CA. Probing determinants of the metal ion selectivity in carbonic anhydrase using mutagenesis. Biochemistry. 2004;43:3979-86.

40. Harding MM. Geometry of metal-ligand interactions in proteins. Acta Cryst. 2001;D57:401-11.

41. Leitgeb S, Straganz GD, Nidetzky B. Biochemical characterization and mutational analysis of the mononuclear non-haem $\mathrm{Fe}^{2+}$ site in Dke1, a cupin-type dioxygenase from Acinetobacter johnsonii. Biochem J. 2009:418:403-11.

42. Chen J, Li W, Wang M, Zhu G, Liu D, Sun F, et al. Crystal structure and mutagenic analysis of GDOsp, a gentisate 1,2-dioxygenase from Silicibacter pomeroyi. Protein Sci. 2008;17:1362-73.

43. Hanahan D. Studies on transformation of Escherichia coli with plasmids. J Mol Biol. 1983;166:557-80.

44. Yang WC, Patel KG, Wong HE, Swartz JR. Simplifying and streamlining Escherichia coli-based cell-free synthesis. Biotechnol Prog. 2012;28:413-20.

45. Kim TW, Keum JW, Oh IS, Choi CY, Park CG, Kim DM. Simple procedures for the construction of a robust and cost-effective cell-free protein synthesis system. J Biotechnol. 2006;126:554-61.

46. Sambrook J, Fritsch EF, Maniatis T. In: Cold Spring Harbor NY, editor Molecular cloning: a laboratory manual $2^{\text {nd }}$ ed. Cold Spring Harbor, NY: Cold Spring Harbor Laboratory Press; 1989.

47. Pfennig N. Rhodopseudomonas globiformis, sp. n., a new species of the Rhodospirillaceae. Arch Microbiol. 1974;100:197-206.

48. Pettersen EF, Goddard TD, Huang CC, Couch GS, Greenblatt DM, Meng EC, et al. UCSF Chimera - a visualization system for exploratory research and analysis. J Comput Chem. 2004;25:1605-12.

49. Zor T, Selinger Z. Linearization of the Bradford protein assay increases its sensitivity: theoretical and experimental studies. Anal Biochem. 1996;236:302-8.

50. Pace CN, Vajdos F, Fee L, Grimsley G, Gray T. How to measure and predict the molar absorption coefficient of a protein. Protein Sci. 1995;4:2411-23.

51. Groemping Y, Hellmann N. Spectroscopic Methods for the Determination of Protein Interactions. Curr Protoc Protein Sci. 2005;39:20.8:20.8.1-20.8.27. doi: 10.1002/0471140864.ps2008s39.

52. Randolph TW. Scale-based normalization of spectral data. Cancer Biomark. 2006:2:135-44

\section{Submit your next manuscript to BioMed Central and take full advantage of:}

- Convenient online submission

- Thorough peer review

- No space constraints or color figure charges

- Immediate publication on acceptance

- Inclusion in PubMed, CAS, Scopus and Google Scholar

- Research which is freely available for redistribution 